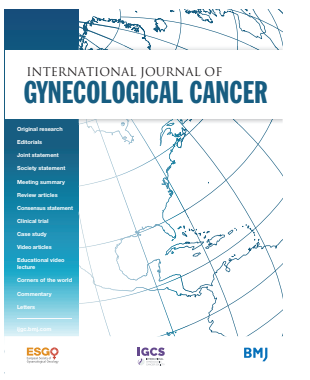

- Additional material is published online only. To view please visit the journal online (http://dx.doi.org/10.1136/ijgc2020-001543).

For numbered affiliations see end of article.

\section{Correspondence to}

Tamara Jones, Institute of Health and Biomedical Innovation, Queensland University of Technology, Kelvin Grove, QLD 4059, Australia; tamara.jones@connect.qut. edu.au

Received 28 April 2020 Revised 29 June 2020 Accepted 1 July 2020 Published Online First 29 July 2020

\section{Check for updates}

(C) IGCS and ESGO 2020. No commercial re-use. See rights and permissions. Published by BMJ.

To cite: Fleming $\mathrm{S}$, Jones $\mathrm{T}$, Janda M, et al. Int J Gynecol Cancer 2020;30:1784-1790.

\title{
Physical activity trajectories following gynecological cancer: results from a prospective, longitudinal cohort study
}

Steven Fleming, ${ }^{1}$ Tamara Jones (D) , ${ }^{2}$ Monika Janda,,${ }^{2,3}$ Dimitrios Vagenas, ${ }^{2}$ Leigh Ward, ${ }^{4}$ Hildegard Reul-Hirche, ${ }^{5}$ Carolina Sandler, ${ }^{2,6}$ Andreas Obermair, ${ }^{7}$ Sandra Hayes ${ }^{8}$

\section{HIGHLIGHTS}

- Two years post-diagnosis, less than one-third of women met physical activity recommendations.

- Only $20 \%$ of women increased or maintained sufficient levels of physical activity during the survivorship period.

- Higher levels of physical activity were associated with higher quality of life.

\section{ABSTRACT \\ Background Participating in physical activity after a diagnosis of cancer is associated with reduced morbidity and improved outcomes. However, declines in, and low levels of, physical activity are well documented in the broader cancer population, but with limited evidence following gynecological cancer.}

Objective To describe physical activity levels from before and up to 2 years after gynecological cancer surgery; to explore the relationship between physical activity patterns and quality of life; and to describe characteristics associated with physical activity trajectories postgynecological cancer.

Methods Women with gynecological cancer $(n=408)$ participated in a prospective study that assessed physical activity and quality of life pre-surgery (baseline), at 6 weeks, and 3, 6, 9, 12, 15, 18 and 24 months postsurgery. Validated questionnaires were used to assess physical activity (Active Australia Survey) and quality of life outcomes (Functional Assessment of Cancer TherapyGeneral). Generalized estimating equation modeling, group-based trajectory analysis, and analysis of variance were used to identify physical activity levels over time, to categorize women into physical activity trajectory groups, and to assess the relationship between physical activity levels and quality of life, respectively.

Results Women had a mean $\pm S D$ age of $60 \pm 11.4$ years at diagnosis, with the majority diagnosed with endometrial cancer $(n=235,58 \%)$ or stage I disease $(n=241,59 \%)$. Most women (80\%) started with and maintained low levels of physical activity (1-10 metabolic equivalent task hours per week), reported no physical activity throughout the follow-up period, or reduced physical activity levels over time. Only $19 \%$ of women maintained or doubled physical activity levels, so that by 24 months post-diagnosis they were engaging in sufficient levels of physical activity. Women with endometrial cancer ( $58 \%$ of the sample) were more likely to be overweight or obese and to report low levels of physical activity or none at all. Higher physical activity levels were associated with higher quality of life $(\mathrm{p}<0.05)$.

Conclusion The low baseline and surveillance levels of physical activity show that the vast majority of gynecological cancer survivors have the ability to improve their physical activity levels. Integration of physical activity advice and support into standard care could lead to gains in quality of life during gynecological cancer survivorship.

\section{INTRODUCTION}

Gynecological cancers (including malignant neoplasms of the ovary, uterus, vulva, vagina, and cervix) account for $\sim 10 \%$ of all new cancer diagnoses and are the third most common cancers for women in developed countries, such as Australia and the United States of America. ${ }^{1}$ However, differences in diagnostic and treatment characteristics between gynecological cancer types, and patient characteristics, may influence post-diagnosis physical activity levels. ${ }^{2}$

Taking part in 150 min moderate-intensity physical activity each week (10 metabolic-equivalenttask hours/week (MET-hours/week)) ${ }^{3-5}$ represents a message consistently promoted to cancer survivors by cancer organizations worldwide. ${ }^{6}{ }^{7}$ Research demonstrates that meeting physical activity recommendations is associated with reduced morbidity and improvements in physical function, psychosocial outcomes, and quality of life during and post-treatment. ${ }^{8} 9$ A recent systematic review and meta-analysis has demonstrated that participating in higher levels of pre- or post-diagnosis physical activity is associated with improved all-cause mortality for 10 cancer types, including gynecological cancer, in comparison with those in the lowest physical activity category. ${ }^{10}$ Post-diagnosis physical activity has also been associated with greater reductions in all-cause mortality, compared with pre-diagnosis physical activity. ${ }^{11}$

Despite these benefits, declines in, and low levels of, physical activity have been documented in people with cancer, with reductions associated with the development of additional, more severe treatmentrelated side effects, poorer treatment response, and 
reduced quality of life. ${ }^{1213}$ Findings from a population-based breast cancer cohort study suggest that while $~ 50 \%$ of cancer survivors are sufficiently active at diagnosis, by 12 months post-diagnosis only one in three is sufficiently active. ${ }^{4}$ Furthermore, $60 \%$ experience declines in physical activity from pre- to post-diagnosis $\left(5.7 \pm 2.9\right.$ months) by an average of 15 MET-hours/week. ${ }^{4}$

Few studies to date have focused on women with gynecological cancer. Those that have were largely cross-sectional, with few high-quality prospective studies. ${ }^{14-16}$ Furthermore, of the limited prospective evidence, two of three studies used retrospective recall of pre-diagnosis physical activity. ${ }^{14-16}$ Findings from the limited evidence involving women with gynecological cancer indicate that the majority are insufficiently active or sedentary post-treatment and experience declines in physical activity of a similar magnitude to those reported in breast cancer cohort studies. ${ }^{16-21}$ There is a clear dearth of prospective information regarding physical activity pre- and post-treatment of gynecological cancer and whether the relationship between physical activity and quality of survival is consistent with other cancer types. Thus, the purpose of this study was to: (1) describe physical activity levels from before and up to 2 years after gynecological cancer surgery; (2) explore the relationship between patterns of physical activity post-gynecological cancer surgery and quality of life; and (3) describe diagnostic and treatment characteristics associated with patterns of physical activity post-gynecological cancer.

\section{METHODS}

\section{Study Design and Subjects}

The Lymphoedema Evaluation in Gynecological cancer Study is a prospective, longitudinal cohort study that followed up 408 women from before to 24 months after surgery for gynecological cancer (endometrial, ovarian, and other: $n=233,112$ and 59, respectively). ${ }^{22}{ }^{23}$ Women with newly diagnosed gynecological cancer (International Classification of Diseases Codes C51-C58) between June 1, 2008 and February 28, 2011, aged 18 years or older, and treated (surgery with or without adjuvant therapy) at one of six hospitals in Australia, were eligible for enrolment. Lower-limb lymphedema was the primary outcome for this cohort study, but physical activity and quality of life were two of several secondary outcomes. Ethical approval was obtained from hospital human research ethics committees (approval numbers: 2008000211, 2007/168, 200842, 1189A/P, 08/16, 10/14, 10/10/RPAH/28).

\section{Timing of Data Collection}

Following written informed consent, data were collected at baseline during the pre-operative visit (survey 1, 1 week pre-diagnostic surgery), and during hospital follow-up visits, at 6 weeks, and 3, $6,9,12,15,18,21$, and 24 months post-surgery (surveys $2-10$, respectively). Follow-up assessments were coordinated with each participant's scheduled appointments; therefore, data were collected a maximum of 10 times over the follow-up period.

\section{Data Collection}

Physical activity was measured using the Active Australia Survey. ${ }^{24}$ This reliable and valid survey asks respondents to estimate the time spent during the previous week walking, and engaging in moderateand vigorous-intensity physical activity. ${ }^{24}$ Reported minutes are weighted by the MET value, the ratio of energy expended from physical activity compared with sitting quietly. MET weights of 3.0, 4.0 , and 7.5 for walking, moderate- and vigorous-intensity activity, respectively, are used to estimate MET-hours/week of physical activity. ${ }^{25} \mathrm{~A}$ clinically relevant difference between groups or over time was defined a priori as $>2$ MET-hours/week. ${ }^{34}$

Participants provided quality of life information using the Functional Assessment of Cancer Therapy-General Survey. ${ }^{26}$ This 27-item validated survey assesses well-being in physical, social/ family, emotional, and functional domains and total quality of life. A clinically relevant difference between groups or over time was defined a priori as $>5$ units ${ }^{27}$ We expected patients reporting higher physical activity would also have better quality of life. Relevant diagnostic, treatment, and patient characteristics were abstracted from medical records by trained research nurses. Patient characteristics relating to socioeconomic status and marital status were collected via a participant-administered questionnaire.

\section{Statistical Analysis}

Analyses were conducted using statistical analysis software (SAS) (SAS Institute, Gary, North Carolina, USA). Proportions were used to describe patient, diagnostic, and treatment characteristics within gynecological cancer groups (endometrial, ovarian, and other, including cervical and vulva/vaginal cancer). Using all available data at each data collection period (baseline plus up to nine follow-up periods), generalized estimating equations with exchangeable correlation structures were used to identify statistically significant trends over time in physical activity, including total physical activity (MET-hours/week) and hours/week of walking, moderate- and vigorous-intensity activity. Women were then categorized into physical activity trajectories based on total MET-hours/ week and group-based modeling theory. The application of such a theory has been used for over 25 years in the development of abnormal psychology and criminology literature, ${ }^{28}{ }^{29}$ but only more recently in epidemiology. ${ }^{3031}$ Descriptive statistics (n, \%) were used to identify relationships between physical activity trajectory groups and patient, diagnostic, and treatment characteristics deemed clinically relevant (>20\% difference between groups).

Analysis of variance was applied to determine if there were differences in mean quality of life (data were normally distributed) between physical activity groups over time. For this analysis, we used baseline data from survey 1 but for the other three time periods, we averaged physical activity and quality of life measures over multiple surveys (surveys 2-3 for period 2, surveys 4-6 for period 3 , and surveys $7-10$ for period 4 ).

\section{RESULTS}

All participants completed baseline assessment, with retention rates of $86 \%, 84 \%$, and $78 \%$ at time periods 2,3 , and 4 , respectively. Characteristics of those with complete (all four time periods) and those with incomplete follow-up data were similar, except that those with incomplete data were more likely to die during the study period, have received chemotherapy, and been diagnosed with stage III disease. ${ }^{22}$ Descriptive statistics of characteristics of the sample $(\mathrm{n}=408)$ are presented in Table 1 (a more extensive summary has been previously presented). ${ }^{22}$ In summary, women had a mean \pm SD age of $60 \pm 11.4$ years at diagnosis, with the majority diagnosed 
Table 1 Descriptive characteristics of the study sample ( $n=408$ women with gynecological cancer)

\begin{tabular}{|c|c|c|c|c|c|c|}
\hline \multirow[b]{2}{*}{ Characteristics } & \multicolumn{2}{|c|}{$\begin{array}{l}\text { Endometrial } \\
(n=235)\end{array}$} & \multicolumn{2}{|c|}{$\begin{array}{l}\text { Ovarian } \\
(n=114)\end{array}$} & \multicolumn{2}{|c|}{$\begin{array}{l}\text { Other* } \\
(n=59)\end{array}$} \\
\hline & $\mathbf{N}$ & $\%$ & $\mathbf{N}$ & $\%$ & $\mathbf{N}$ & $\%$ \\
\hline \multicolumn{7}{|l|}{ Stage } \\
\hline 1 & 165 & 70.2 & 28 & 24.6 & 48 & 81.4 \\
\hline II & 26 & 11.1 & 14 & 12.3 & 1 & 1.7 \\
\hline III & 27 & 11.5 & 53 & 46.5 & 4 & 6.8 \\
\hline IV & 13 & 5.5 & 14 & 12.3 & 0 & 0.0 \\
\hline Missing & 4 & 1.7 & 5 & 4.4 & 6 & 10.2 \\
\hline \multicolumn{7}{|l|}{ Age† } \\
\hline$<60$ years & 104 & 44.3 & 52 & 45.6 & 46 & 78.0 \\
\hline$\geq 60$ years & 131 & 55.7 & 62 & 54.4 & 13 & 22.0 \\
\hline \multicolumn{7}{|c|}{ Body mass index $†\left(\mathrm{~kg} / \mathrm{m}^{2}\right)$} \\
\hline Healthy weight $(<25)$ & 38 & 16.2 & 43 & 37.7 & 18 & 30.5 \\
\hline Overweight (25-30) & 52 & 22.1 & 38 & 33.3 & 21 & 35.6 \\
\hline Obese $(>30)$ & 145 & 61.7 & 31 & 27.2 & 20 & 33.9 \\
\hline Missing & 0 & 0.0 & 2 & 1.8 & 0 & 0.0 \\
\hline \multicolumn{7}{|c|}{ Physical activity category $\ddagger$ at baseline } \\
\hline Sedentary & 46 & 19.6 & 20 & 17.5 & 10 & 16.9 \\
\hline Low & 87 & 37.0 & 40 & 35.1 & 18 & 30.5 \\
\hline Moderate & 21 & 8.9 & 13 & 11.4 & 10 & 16.9 \\
\hline High & 28 & 11.9 & 23 & 20.2 & 9 & 15.3 \\
\hline Missing & 53 & 22.6 & 18 & 15.8 & 12 & 20.4 \\
\hline
\end{tabular}

*Other: cervical $(n=37)$ and vulva/vaginal $(n=22)$.

†Significant chi-square $<0.05$.

†Physical activity categories: sedentary <0.67 metabolic hours per week (MET-hours/week); low 0.67-10 MET-hours/week; moderate >10-20

MET-hours/week and high >20 MET-hours/week.

with endometrial cancer $(n=235,58 \%)$ or stage I disease $(n=241$, $59 \%)$. Most were post-menopausal $(n=326,80 \%)$ and either overweight or obese (body mass index $\geq 25 \mathrm{~kg} / \mathrm{m}^{2} ; \mathrm{n}=307,75 \%$ ). Higher proportions of women with cervical or vulva/vaginal cancer were aged $<60$ years, compared with those with ovarian or endometrial cancer. Compared with other gynecological cancers, higher proportions of women with ovarian cancer were diagnosed with stage III+ disease and higher proportions of overweight and obese women were diagnosed with endometrial cancer. Overall, these characteristics are representative of the wider gynecological cancer population. Baseline physical activity was similar across gynecological cancers, with up to $68 \%$ of women who provided baseline physical activity data classified as sedentary $(<0.67 \mathrm{MET}$-hours/week $)$ or participating in low levels (0.67-10 MET-hours/week) of weekly physical activity. ${ }^{3-5}$

Table 2 reports descriptive statistics on physical activity from baseline to 24 months post-diagnosis, showing that mean total physical activity (MET-hours/week) increased from baseline to $>15$ months post-diagnosis $(p<0.002)$, with increases in moderate(including walking, $\mathrm{p}<0.002$ ) and vigorous-intensity activity $(p<0.02)$ contributing to these changes. A steady increase in physical activity was observed between baseline and 6-12 months post-diagnosis, equating to a twofold increase in MET-hours/week. When calculating this increase according to means, the increase in MET-hours/week is largely driven by increases in walking, as only small changes in moderate- and vigorous-intensity physical activity were observed. Group-based trajectory analysis of physical activity from baseline to 15-24 months post-diagnosis found five groups provided the best fit, and quadratic trajectories provided the most parsimonious model. Figure 1 shows the five trajectories of physical activity summarizing MET-hours/week including walking, moderate- and vigorous-intensity activity. Group 1 (labeled 'sedentariates') and group 2 (labeled 'physically inactive') remained flat over the post-diagnosis study period. Sedentariates $(n=15,3.7 \%)$ reported virtually no physical activity and experienced no change over the 2 year follow-up. The physically inactive $(n=297,72.8 \%)$ started and remained at a relatively low level ( $<10$ MET-hours/ week). Group 3, labeled 'doublers' ( $\mathrm{n}=70,17.2 \%)$ started at $\sim 14$ MET-hours/week but doubled physical activity over the 2-year study period, while group 4, 'downsizers' $(n=16,3.9 \%)$ reported high levels of baseline physical activity but reduced activity by twothirds over the 2-year follow-up period. Group 5 (labeled 'enthusiasts'; $n=10,2.5 \%$ ) started and remained at high physical activity levels ( 55 MET-hours/week) throughout the follow-up period.

Figure 2 presents descriptive quality of life statistics for the five physical activity groups from baseline to $15-24$ months postdiagnosis. There were significant differences $(p<0.05)$ in mean quality of life between groups at baseline, with quality of life highest 
Table 2 Physical activity levels in hours per week from baseline to 24 months post-diagnosis of women with gynecological cancer

\begin{tabular}{|c|c|c|}
\hline Physical activity & Median (IQR) & Mean (SD) \\
\hline \multicolumn{3}{|l|}{ Walking (hours/week)* } \\
\hline Baseline $(n=325)$ & 1.17 (0.00 to 3.00$)$ & $2.18(2.95)$ \\
\hline $\begin{array}{l}6 \text { Weeks to } 3 \text { months } \\
(n=323)\end{array}$ & 1.83 (0.77 to 4.00$)$ & $2.79(3.00)$ \\
\hline $\begin{array}{l}6 \text { to } 12 \text { months } \\
(\mathrm{n}=333)\end{array}$ & 2.00 (0.89 to 4.00$)$ & $2.88(2.92)$ \\
\hline $\begin{array}{l}15 \text { to } 24 \text { months } \\
(n=311)\end{array}$ & 2.04 (0.81 to 3.99$)$ & $2.79(2.74)$ \\
\hline \multicolumn{3}{|l|}{ Moderate (hours/week) } \\
\hline Baseline $(n=325)$ & 0.00 (0.00 to 0.00$)$ & $0.40(1.27)$ \\
\hline $\begin{array}{l}6 \text { Weeks to } 3 \text { months } \\
(n=323)\end{array}$ & 0.00 (0.00 to 0.00$)$ & $0.36(1.17)$ \\
\hline $\begin{array}{l}6 \text { to } 12 \text { months } \\
(n=333)\end{array}$ & 0.00 (0.00 to 0.33$)$ & $0.47(1.08)$ \\
\hline $\begin{array}{l}15 \text { to } 24 \text { months } \\
(n=311)\end{array}$ & 0.00 (0.00 to 0.50$)$ & $0.52(1.11)$ \\
\hline \multicolumn{3}{|l|}{ Vigorous (hours/week)* } \\
\hline Baseline $(n=325)$ & 0.00 (0.00 to 0.00$)$ & $0.34(1.11)$ \\
\hline $\begin{array}{l}6 \text { Weeks to } 3 \text { months } \\
(n=323)\end{array}$ & 0.00 (0.00 to 0.00$)$ & $0.30(1.22)$ \\
\hline $\begin{array}{l}6 \text { to } 12 \text { months } \\
(n=333)\end{array}$ & 0.00 (0.00 to 0.50$)$ & $0.48(1.14)$ \\
\hline $\begin{array}{l}15 \text { to } 24 \text { months } \\
(n=311)\end{array}$ & 0.00 (0.00 to 0.50$)$ & $0.49(1.04)$ \\
\hline \multicolumn{3}{|l|}{$\begin{array}{l}\text { Total physical activity } \\
\text { (MET-hours/week)* }^{*}\end{array}$} \\
\hline Baseline $(n=325)$ & 4.50 (1.00 to 13.75$)$ & $10.69(15.26)$ \\
\hline $\begin{array}{l}6 \text { Weeks to } 3 \text { months } \\
(n=323)\end{array}$ & 7.38 (3.00 to 15.31$)$ & $12.08(14.64)$ \\
\hline $\begin{array}{l}6 \text { to } 12 \text { months } \\
(n=333)\end{array}$ & 9.33 (3.67 to 20.04) & $14.12(15.05)$ \\
\hline $\begin{array}{l}15 \text { to } 24 \text { months } \\
(n=311)\end{array}$ & 10.00 (3.87 to 20.06$)$ & $14.11(14.20)$ \\
\hline
\end{tabular}

*Statistically significant trends were observed over time for mean walking $(p<0.002)$, vigorous-intensity activity $(p<0.02)$, and metabolic hours per week $(p<0.002)$.

for enthusiasts and lowest for the physically inactive (Tukey honest significant difference test $=15.9(95 \% \mathrm{Cl} 0.54$ to 31.2$)$. For the three follow-up periods, there were clinically relevant ( $>5$ units) differences between groups, with enthusiasts continuing to report the highest quality of life compared with all other groups, although differences were not supported statistically. Also, of note, the physically inactive $(p<0.01)$ and doublers $(p>0.05)$ reported clinically relevant improvements in mean quality of life over time. Table 3 shows higher proportions of women aged $<60$ years and obese women in the sedentariates group compared with other groups. Women in the enthusiasts group were more likely to be diagnosed with ovarian cancer, have stage III disease, have had lymph node removal, and/or received chemotherapy as their only form of adjuvant treatment.

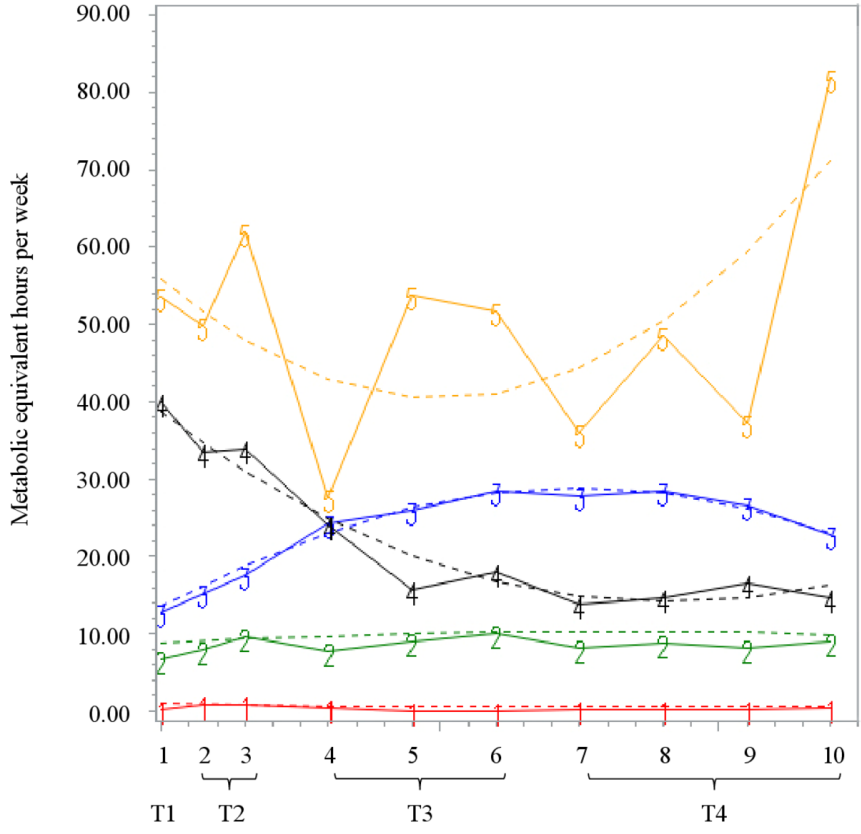

Figure 1 Trajectories of physical activity levels from prediagnosis to 24 months post-diagnosis of gynecological cancer. Group 1 'sedentariates' $=3.7 \%$ of women; group 2 'physically inactive' $=72.8 \%$; group 3 'doublers' $=17.2 \%$; group 4 'downsizers' $=3.9 \%$; group 5 'enthusiasts' $=2.5 \%$. T1=baseline; T2=6 weeks to 3 months post-diagnosis; T3=6 to 12 months post-diagnosis; T4=15 to 24 months postdiagnosis.

\section{DISCUSSION}

On average, there was an increase in time spent walking and engaging in moderate- and vigorous-intensity physical activity from before to 24 months after surgery for gynecological cancer. However, trajectory analyses showed that these results are due to high and increasing levels of physical activity among a small group. Very few women reported sufficient physical activity pre- or

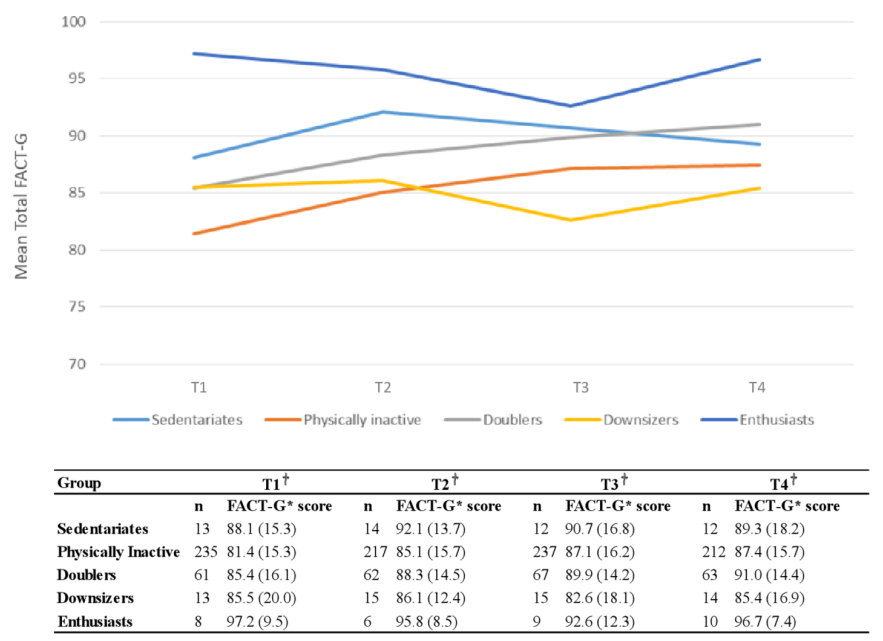

Figure 2 Quality-of-life from baseline to 24 months postdiagnosis of women with gynecological cancer by physical activity groups $\mathrm{T} 1=$ baseline; T2 $=6$ weeks to 3 months postdiagnosis; T3=6 to 12 months post-diagnosis; T4=15 to 24 months post-diagnosis. *FACT-G=functional assessment of cancer therapy-general; †mean (SD). 
Table 3 Unadjusted relationships* between diagnostic, treatment and patient characteristics and membership in each of the five physical activity trajectory groups

\begin{tabular}{|c|c|c|c|c|c|}
\hline & $\begin{array}{l}\text { Sedentariates } \\
(n=15)\end{array}$ & $\begin{array}{l}\text { Physically inactive } \\
(\mathrm{n}=297)\end{array}$ & $\begin{array}{l}\text { Doublers } \\
(\mathrm{n}=70)\end{array}$ & $\begin{array}{l}\text { Downsizers } \\
(n=16)\end{array}$ & $\begin{array}{l}\text { Enthusiasts } \\
(n=10)\end{array}$ \\
\hline & $\%$ & $\%$ & $\%$ & $\%$ & $\%$ \\
\hline \multicolumn{6}{|l|}{ Age } \\
\hline$<60$ years & 80.0 & 50.8 & 51.4 & 43.8 & 50.0 \\
\hline$\geq 60$ years & 20.0 & 49.2 & 48.6 & 56.2 & 50.0 \\
\hline \multicolumn{6}{|l|}{ Cancer type } \\
\hline Endometrial & 53.3 & 61.6 & 47.1 & 56.2 & 20.0 \\
\hline Ovary & 33.3 & 24.2 & 40.0 & 25.0 & 50.0 \\
\hline Other & 13.4 & 14.2 & 12.9 & 18.8 & 30.0 \\
\hline \multicolumn{6}{|l|}{ Stage } \\
\hline 1 & 33.3 & 62.6 & 51.4 & 56.2 & 50.0 \\
\hline ॥ & 6.7 & 10.8 & 7.1 & 0.0 & 0.0 \\
\hline III & 26.7 & 18.5 & 24.3 & 18.8 & 40.0 \\
\hline IV & 13.3 & 4.7 & 14.3 & 25.0 & 10.0 \\
\hline Missing & 20.0 & 3.4 & 2.9 & 0.0 & 0.0 \\
\hline \multicolumn{6}{|c|}{ Receipt of adjuvant therapy } \\
\hline No & 33.3 & 54.2 & 41.4 & 56.2 & 40.0 \\
\hline Chemotherapy only & 33.3 & 22.2 & 40.0 & 25.0 & 60.0 \\
\hline Radiation only & 13.4 & 8.4 & 4.3 & 12.5 & 0.0 \\
\hline Both & 20.0 & 15.2 & 14.3 & 6.3 & 0.0 \\
\hline Missing & 0.0 & 0.0 & 0.0 & 0.0 & 0.0 \\
\hline \multicolumn{6}{|l|}{ Body mass index } \\
\hline Normal weight $<25$ & 6.7 & 23.2 & 32.9 & 25.0 & 20.0 \\
\hline Overweight (25-30) & 20.0 & 28.3 & 22.9 & 25.0 & 40.0 \\
\hline Obese $(\geq 30)$ & 73.3 & 47.8 & 44.2 & 50.0 & 40.0 \\
\hline Missing & 0.0 & 0.7 & 0.0 & 0.0 & 0.0 \\
\hline
\end{tabular}

*Only characteristics with clinically relevant differences between physical activity trajectory groups have been presented.

post-gynecological cancer surgery. Almost $70 \%$ were sedentary or insufficiently active at diagnosis, and by 24 months post-diagnosis fewer than one in three met physical activity recommendations (that is, $>150 \mathrm{~min} /$ week of moderate-intensity physical activity, equivalent to $\geq 10$ MET-hours/week). Further, when grouped according to post-cancer physical activity patterns, only $20 \%$ increased or maintained sufficient physical activity levels throughout the survivorship period. The majority were insufficiently active (physically Inactive) or sedentary (sedentariates) pre-diagnosis and remained so 24 months post-diagnosis. For $4 \%$ of women, diagnosis and/or gynecological cancer treatment was associated with steep declines in physical activity, so that by $6-12$ months post-diagnosis their average weekly MET-hours/week were half their pre-diagnosis levels (downsizers, 3.9\%). Together, downsizers, sedentariates, and physically inactive accounted for $>80 \%$ of our gynecological cancer sample.

Findings suggest that physical activity levels are probably associated with quality of life, with those reporting the highest levels of physical activity (enthusiasts) also reporting the highest quality of life from before to 24 months after diagnosis. The positive relationship between physical activity and quality of life has been previously demonstrated among several cancer cohorts, including patient with gynecological cancer. ${ }^{17} 3233$ However, longitudinal findings from this paper contribute to the evidence by demonstrating the positive relationship between change in physical activity and quality of life improvements. Results show those reporting increases in physical activity (physically inactive and doublers) achieved commensurate increases in quality of life. Additionally, while the physically inactive failed to meet physical activity recommendations, increases in physical activity were still associated with quality of life improvements. These findings highlight the importance of recommending physical activity and show that some activity is better than no activity, which is in line with internationally endorsed physical activity recommendations. ${ }^{7345}$ Improvements in quality of life may be achieved through avoiding inactivity, engaging in as many physical activities as possible, and progressing towards and maintaining physical activity levels.

The physical activity levels reported here are consistent with those reported following breast cancer diagnosis, ${ }^{4}$ but differences between gynecological cancers were identified. Specifically, 
sedentariates had a higher proportion of women with endometrial cancer and obese women (double that of other groups). In contrast, enthusiasts had a higher proportion of women with ovarian cancer, those $>60$ years, diagnosed with stage III disease, and receiving chemotherapy. These findings suggest that gynecological cancer type, or characteristics associated with developing particular gynecological cancers may contribute to the relationship observed between characteristics and physical activity behaviors. For example, obesity is a significant risk factor for endometrial cancer $^{36}{ }^{37}$ and women in the sedentariates (who exercised less) were more likely to be obese with endometrial cancer; however, this is based on a small subgroup $(n=15)$.

Understanding the characteristics of physical activity trajectory groups provides insight into how to individually tailor interventions from a behavior change perspective, as well as determining the initial level of physical activity and capacity for change. For example, obese women with endometrial cancer may benefit from the incorporation of physical activity into cancer care by preventing chronic disease and improving survivorship outcomes. Thus, physical activity interventions may focus on understanding lifestyle behaviors (lack of physical activity and obesity) and building self-efficacy. Specifically, the level of physical activity may start low, with the intervention duration period accommodating movement from precontemplation through to maintenance and termination stages of behavior change ${ }^{38}$ Conversely, women with more advanced ovarian cancer may benefit from interventions focusing on the role of physical activity in the management of physical and psychological side effects during and after treatment. Given the higher proportions of women with ovarian cancer among the enthusiasts, it is plausible that the intervention should target maintenance of physical activity and prevention of declines, together with developing self-efficacy and strategies for overcoming novel exercise barriers arising as a consequence of treatment. However, the vast majority of participants $(80 \%)$ were insufficiently active and unable to increase or maintain sufficient physical activity levels. Therefore, there is scope for physical activity interventions to be delivered to all women diagnosed with gynecological cancer. Flexible approaches to delivery and individualized interventions could allow for targeted support for women with differing demographic and diagnostic characteristics.

Of equal importance is understanding determinants of physical activity trajectories. Particularly, why some women increase their physical activity (doublers), whereas others decrease (downsizers). Clinical factors, including lymphedema, anthropometric factors (eg, body mass), and social factors (eg, social support networks), may contribute to physical activity trajectory and inform treatment strategies. To date, lifestyle intervention trials in the gynecological cancer setting are scarce. Nonetheless, findings from published trials suggest that physical activity support or exercise intervention during and after gynecological cancer treatment is feasible, safe, and effective at improving physical activity and health outcomes. ${ }^{39}{ }^{40}$ Improved understanding of determinants of physical activity trajectories will inform the design and testing of future intervention trials, which if proved to be successful, can be translated to clinical practice.

Key strengths of this work include its prospective, longitudinal design with a 2-year post-diagnosis follow-up, recruitment of a sample with characteristics generalizable to the wider gynecological cancer population, and the classification of women based on post-diagnosis physical activity patterns. Physical activity was not assessed objectively, and self-reported physical activity levels are more likely to be overestimated ${ }^{41}$, placing these findings in the conservative direction. Additionally, while these data provide insufficient power for adjusted analyses, results provide pilot findings to support future research, including more in-depth analysis of characteristics associated with physical activity trajectories. Thus, these epidemiological findings represent unique and important contributions to the gynecological survivorship field. Furthermore, while findings reflect associations rather than causal relationships, they contribute to a compelling and growing evidence demonstrating the potential for improving cancer survivorship by incorporating physical activity intervention into standard care. Future research must focus on developing and implementing safe and cost-effective strategies to influence changes in physical activity during and beyond cancer treatment.

In summary, findings demonstrate that the vast majority of gynecological cancer survivors are insufficiently active and have significant capacity for improvement in physical activity, highlighting a clear need for the formal integration of physical activity advice and support into standard gynecological cancer care. Understanding how to translate this evidence into practice is an important next step for researchers, clinicians, policy makers and cancer survivors.

\section{Author affiliations \\ ${ }^{1}$ College of Public Health, University of Kentucky, Lexington, Kentucky, USA ${ }^{2}$ Institute of Health and Biomedical Innovation, Queensland University of Technology, Kelvin Grove, Queensland, Australia \\ ${ }^{3}$ Centre for Health Services Research, The University of Queensland Faculty of Medicine, Brisbane, Queensland, Australia \\ ${ }^{4}$ School of Chemistry and Molecular Biosciences, The University of Queensland, Saint Lucia, Queensland, Australia \\ ${ }^{5}$ Physiotherapy Department, Royal Brisbane and Women's Hospital, Brisbane, Queensland, Australia \\ ${ }^{6}$ School of Exercise and Nutrition Sciences, Queensland University of Technology, Brisbane, Queensland, Australia \\ ${ }^{7}$ Queensland Centre of Gynecological Research, Royal Brisbane and Women's Hospital, Brisbane, Queensland, Australia \\ ${ }^{8}$ Menzies Health Institute Queensland, Griffith University, Brisbane, Queensland, Australia}

Acknowledgements We would like to acknowledge the invaluable contributions of the women who participated in this study.

Contributors All authors have provided a substantial contribution to this work.

Funding This work was supported by project grants and fellowships from Cancer Council Australia, Cancer Australia, Greenslopes Hospital Research Foundation, Wesley Research Foundation, National Breast Cancer Foundation (SH), Cancer Council Queensland (SH) and the National Health and Medical Research Foundation (MJ).

Competing interests $\mathrm{AO}$ is the founder and managing director of SurgicalPerformance Pty Ltd, an Australian, private company that provides surgeons with a platform for collection of surgical outcome audit data; $\mathrm{A} 0$ received travel grants from the 0.R. Company (formerly Tyco Healthcare) and is a consultant for Covidien, NSW, Australia.

Patient consent for publication Not required.

Ethics approval All procedures performed in studies involving human participants were in accordance with the ethical standards of the institutional and/or national research committee and with the 1964 Helsinki declaration and its later amendments or comparable ethical standards.

Provenance and peer review Not commissioned; externally peer reviewed. 


\section{Original research}

Data availability statement Data are available upon reasonable request. Deidentified participant data available from Tamara Jones upon reasonable request (see Corresponding author information).

\section{ORCID iD}

Tamara Jones http://orcid.org/0000-0002-4854-0968

\section{REFERENCES}

1 U.S. Cancer Statistics Working Group. United States cancer statistics: 1999-2013 incidence and mortality web-based report. Atlanta: U.S. Department of Health and Human Services, Centers for Disease Control and Prevention and National Cancer Institute, 2016.

2 Australian Institute of Health and Welfare, Cancer Australia. Gynaecological cancers in Australia: an overview. Canberra: AlHW, 2012.

3 Ainsworth BE, Haskell WL, Whitt MC, et al. Compendium of physical activities: an update of activity codes and Met intensities. Med Sci Sports Exerc 2000;32:S498-516.

4 Hair BY, Hayes S, Tse C-K, et al. Racial differences in physical activity among breast cancer survivors: implications for breast cancer care. Cancer 2014;120:2174-82.

5 Harrison S, Hayes SC, Newman B. Level of physical activity and characteristics associated with change following breast cancer diagnosis and treatment. Psychooncology 2009;18:387-94.

6 World Health Organization. Global recommendations on physical activity for health. Geneva: World Health Organization, 2010.

7 Rock CL, Doyle C, Demark-Wahnefried W, et al. Nutrition and physical activity guidelines for cancer survivors. CA Cancer J Clin 2012;62:242-74.

8 Phillips SM, Alfano CM, Perna FM, et al. Accelerating translation of physical activity and cancer survivorship research into practice: recommendations for a more integrated and collaborative approach. Cancer Epidemiol Biomarkers Prev 2014;23:687-99.

9 Hayes SC, Newton RU, Spence RR, et al. The exercise and sports science Australia position statement: exercise medicine in cancer management. J Sci Med Sport 2019;22:1175-99.

10 Friedenreich CM, Stone CR, Cheung WY, et al. Physical activity and mortality in cancer survivors: a systematic review and meta-analysis. JNCI Cancer Spectr 2020;4.

$11 \mathrm{Li} \mathrm{T}$, Wei S, Shi Y, et al. The dose-response effect of physical activity on cancer mortality: findings from 71 prospective cohort studies. $\mathrm{Br}$ J Sports Med 2015.

12 Courneya KS, Segal RJ, McKenzie DC, et al. Effects of exercise during adjuvant chemotherapy on breast cancer outcomes. Med Sci Sports Exerc 2014;46:1744-51.

13 Schmitz KH, Speck RM, Rye SA, et al. Prevalence of breast cancer treatment sequelae over 6 years of follow-up: the pulling through study. Cancer 2012;118:2217-25.

14 Abbott SE, Camacho F, Peres LC, et al. Recreational physical activity and survival in African-American women with ovarian cancer. Cancer Causes Control 2018;29:77-86.

15 Beesley VL, Price MA, Butow PN, et al. Physical activity in women with ovarian cancer and its association with decreased distress and improved quality of life. Psychooncology 2011;20:1161-9.

16 Ryan M, White K, Roydhouse JK, et al. A description of the nutritional status and quality of life of Australian gynaecological cancer patients over time. Eur J Oncol Nurs 2012;16:453-9.

17 Beesley VL, Eakin EG, Janda M, et al. Gynecological cancer survivors' health behaviors and their associations with quality of life. Cancer Causes Control 2008;19:775-82.

18 Courneya KS, Karvinen KH, Campbell KL, et al. Associations among exercise, body weight, and quality of life in a populationbased sample of endometrial cancer survivors. Gynecol Oncol 2005;97:422-30.

19 Stevinson C, Faught W, Steed H, et al. Associations between physical activity and quality of life in ovarian cancer survivors. Gynecol Oncol 2007;106:244-50.

20 Nayak P, Vernon SW, Savas LS, et al. Functional impairment and physical activity adherence among gynecologic cancer survivors: a population-based study. Int J Gynecol Cancer 2016;26:381-8.
21 Lin K-Y, Edbrooke L, Granger CL, et al. The impact of gynaecological cancer treatment on physical activity levels: a systematic review of observational studies. Braz J Phys Ther 2019;23:79-92.

22 DiSipio T, Janda M, Hayes S, et al. The lymphedema evaluation in gynecological cancer study (LEGS): design of a prospective, longitudinal, cohort study. Cancer Res Front 2015;1:104-18.

23 Hayes SC, Janda M, Ward LC, et al. Lymphedema following gynecological cancer: results from a prospective, longitudinal cohort study on prevalence, incidence and risk factors. Gynecol Oncol 2017;146:623-9.

24 Australian Institute of Health Welfare. The active Australia survey: a guide and manual for implementation, analysis and reporting. Canberra: AlHW, 2003.

25 IPAQ. Guidelines for data processing and analysis of the International physical activity questionnaire, 2005.

26 Cella DF, Tulsky DS, Gray G, et al. The functional assessment of cancer therapy scale: development and validation of the general measure. J Clin Oncol 1993;11:570-9.

27 Brucker PS, Yost K, Cashy J, et al. General population and cancer patient norms for the Functional Assessment of Cancer TherapyGeneral (FACT-G). Eval Health Prof 2005;28:192-211.

28 Land KC, McCall PL, Nagin DS. A comparison of Poisson, negative binomial, and semiparametric mixed poisson regression models: with empirical applications to criminal careers data. Sociological Methods \& Research 1996;24:387-442.

29 Nagin DS, Land KC. Age, criminal careers, and population heterogeneity: specification and estimation of a nonparametric, mixed Poisson MODEL* . Criminology 1993;31:327-62.

30 Zimmer Z, Martin LG, Jones BL, et al. Examining late-life functional limitation trajectories and their associations with underlying onset, recovery, and mortality. J Gerontol B Psychol Sci Soc Sci 2014;69:275-86.

31 Pines HA, Gorbach PM, Weiss RE, et al. Sexual risk trajectories among MSM in the United States: implications for preexposure prophylaxis delivery. J Acquir Immune Defic Syndr 2014;65:579-86

32 Phillips SM, McAuley E. Associations between self-reported postdiagnosis physical activity changes, body weight changes, and psychosocial well-being in breast cancer survivors. Support Care Cancer 2015;23:159-67.

33 DiSipio T, Hayes S, Battistutta D, et al. Patterns, correlates, and prognostic significance of quality of life following breast cancer. Psychooncology 2011;20:1084-91.

34 Campbell KL, Winters-Stone KM, Wiskemann J, et al. Exercise guidelines for cancer survivors: consensus statement from international multidisciplinary roundtable. Med Sci Sports Exerc 2019;51:2375-90.

35 US Department of Health and Human Services. Physical activity guidelines for Americans. 2nd ed. Wasington, DC: US Dept of Health and Human Services, 2018.

36 Wise MR, Jordan V, Lagas A, et al. Obesity and endometrial hyperplasia and cancer in premenopausal women: a systematic review. Am J Obstet Gynecol 2016;214:689.e1-689.e17.

37 Arnold M, Jiang L, Stefanick ML, et al. Duration of adulthood overweight, obesity, and cancer risk in the women's health Initiative: a longitudinal study from the United States. PLoS Med 2016;13:e1002081.

38 Prochaska JO, Velicer WF. The transtheoretical model of health behavior change. Am J Health Promot 1997;12:38-48.

39 Newton MJ, Hayes SC, Janda M, et al. Safety, feasibility and effects of an individualised walking intervention for women undergoing chemotherapy for ovarian cancer: a pilot study. BMC Cancer 2011;11:389.

40 Smits A, Lopes A, Das N, et al. The effect of lifestyle interventions on the quality of life of gynaecological cancer survivors: a systematic review and meta-analysis. Gynecol Oncol 2015;139:546-52.

41 Godino JG, Watkinson C, Corder K, et al. Awareness of physical activity in healthy middle-aged adults: a cross-sectional study of associations with sociodemographic, biological, behavioural, and psychological factors. BMC Public Health 2014;14:421. 